This item was submitted to Loughborough's Research Repository by the author.

Items in Figshare are protected by copyright, with all rights reserved, unless otherwise indicated.

\title{
Effects of electroplating on the mechanical properties of stereolithography and laser sintered parts
}

PLEASE CITE THE PUBLISHED VERSION

PUBLISHER

(C) Emerald Group Publishing Limited

LICENCE

CC BY-NC-ND 4.0

REPOSITORY RECORD

Saleh, Naguib, Neil Hopkinson, Richard J.M. Hague, and Sean Wise. 2019. "Effects of Electroplating on the Mechanical Properties of Stereolithography and Laser Sintered Parts". figshare.

https://hdl.handle.net/2134/3507. 
This item was submitted to Loughborough's Institutional Repository by the author and is made available under the following Creative Commons Licence conditions.

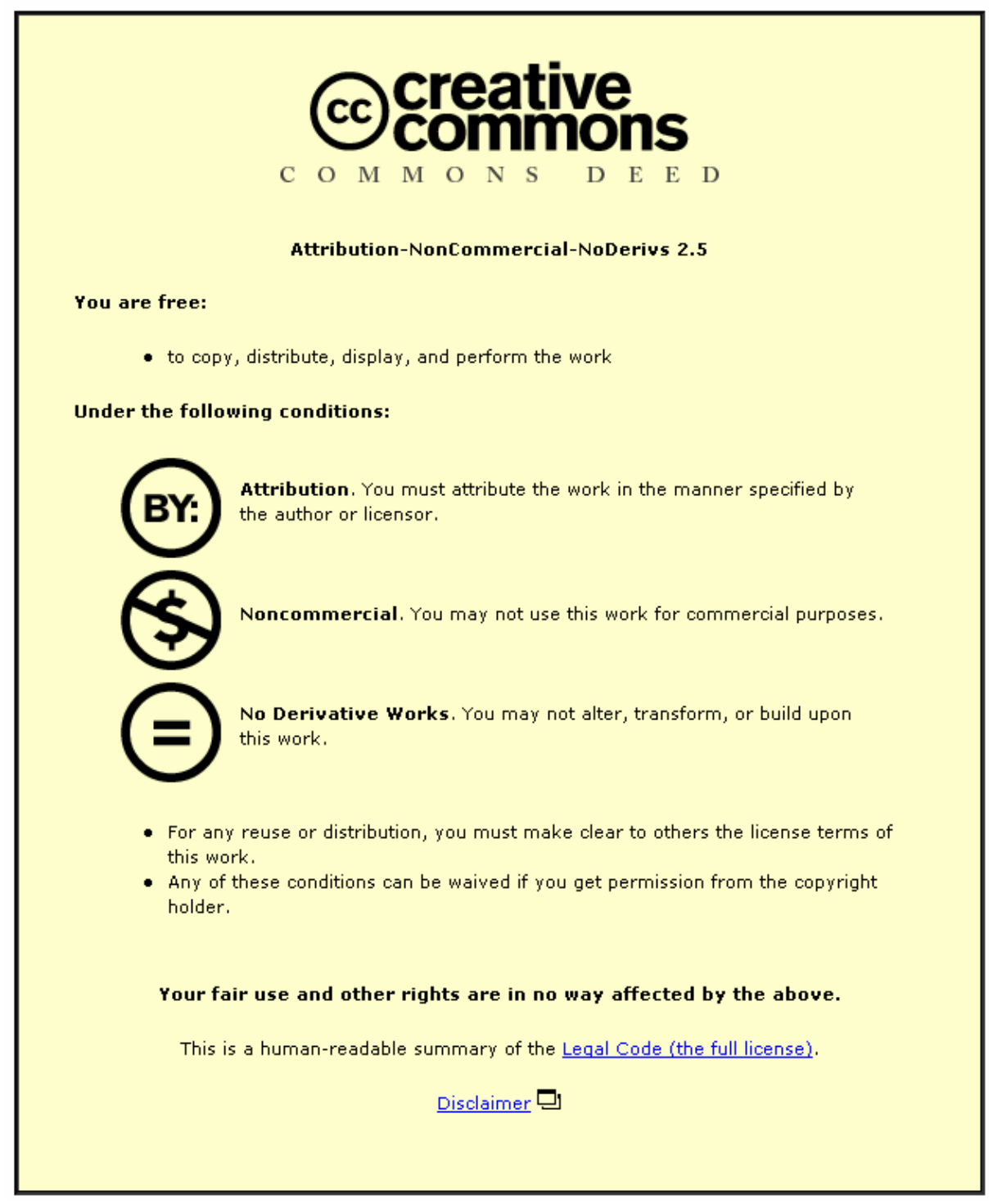

For the full text of this licence, please go to: http://creativecommons.org/licenses/by-nc-nd/2.5/ 


\title{
Effects of Electroplating on the Mechanical Properties of Stereolithography and Laser Sintered Parts
}

\author{
Saleh, $\mathrm{N}^{*}$, Hopkinson, $\mathrm{N}^{\star *}$, Hague, $\mathrm{RJM} \mathrm{M}^{\star * *}$ \& Wise $\mathrm{S}^{* \star * *}$. \\ * Corresponding Author: Mr. Naguib Saleh, Research Associate, Wolfson School of Mechanical \& \\ Manufacturing Engineering, Loughborough University, Leicestershire, LE11 3TU, UK. E-mail: \\ N.Saleh@lboro.ac.uk \\ ** Dr. Richard Hague, Lecturer, Wolfson School of Mechanical \& Manufacturing Engineering, \\ Loughborough University. E-mail: R.Hague@lboro.ac.uk \\ *** Dr. Neil Hopkinson, Lecturer, Wolfson School of Mechanical \& Manufacturing Engineering, \\ Loughborough University. E-mail: N.Hopkinson@lboro.ac.uk \\ **** Mr. Sean Wise, Repliform Inc., MD, USA. E-mail:
}

\section{Abstract}

This paper provides a quantitative and qualitative assessment of the effects of electroplating on polymer parts made by stereolithography and laser sintering. A series of test samples were coated with copper and nickel with varying thickness. Thicker coatings $(120 \mu \mathrm{m})$ were reproduced with a repeatability that should not adversely affect the tolerances with which such parts may be produced given the tolerances of the initial rapid prototyping processes themselves. Thinner coatings $(20 \mu \mathrm{m})$ resulted in a smother surface finish than thicker coatings for stereolithography parts, however the converse was true for laser-sintered parts. Composite theory was used to predict that thicker coating would lead to higher Young's modulus in parts and this was shown to be true in physical tests although the practical values were lower than the predicted values especially for thicker coatings. Physical tests also confirmed that thicker coatings increased UTS and impact energy but had a minimal effect on the ductility of parts.

\section{Keywords}

Rapid Prototyping, Rapid Manufacturing, Stereolithography, Laser Sintering, Electroplating, Surface Roughness

\section{Introduction}

\subsection{Rapid Prototyping \& Rapid Manufacturing}

Rapid Prototyping (RP) is the collective name for a set of different technologies and processes used to manufacture models directly from a three-dimensional (3D) Computer Aided Design (CAD) model by constructively building them in layers. The RP processes include, amongst others, Stereolithography (SL), Laser Sintering (LS), Fused Deposition Modelling (FDM) and 3-Dimensional Printing (3DP). Other associated names include Solid Freeform Fabrication (SFF) and Layered Manufacturing (LM). RP technologies have gained diversity, complexity, sophistication and popularity since their introduction in the late 1980's. The use of $\mathrm{RP}$ in product design and development has had a significantly positive effect and has been shown to reduce development costs by 40 to $70 \%$ and the time to market by as much as 90\% [Dulieu and Fulton, 2000]. RP parts have been used in a range of 
areas such as design visualisation, pattern building, assembly verification and functional testing. However, it is not the aim of this paper to describe the various RP processes, as they are well documented elsewhere [Cooper, 2001; Groover, 2002].

The concept of Rapid Manufacturing (RM) - the production of end-use parts from additive manufacturing systems - is evolving from RP. The principal advantage of the additive manufacturing processes (including most, but not all, of the currently available RP techniques) is the ability to manufacture parts of virtually any complexity of geometry entirely without the need for tooling. If this principle were extended to true manufacturing processes then the opportunities for product design and manufacturing are immense.

Though some well-documented 'Rapid Manufacturing' is being undertaken today, these examples are being undertaken with existing RP systems [Wholers, 2001; Masers and Mathy, 2002]. However, no current RP technology can be truly considered as a manufacturing process as there are several limitations that impede their use as manufacturing systems. The most important areas of concern include:

1. The machines are designed for prototyping and not for manufacturing which means that they are working at slow speed, relatively low accuracy and produce parts with poor surface finish [Hague, 2002]

2. Current high cost of machines (up to $£ 750 \mathrm{~K}$ ) and materials ( $£ 160 / \mathrm{kg}$ for SL resins)

3. The limited number of materials (around 46 SL \& 15 LS materials in USA \& Europe). This is small compared to other manufacturing techniques such as injection moulding that has thousands of available materials.

4. The very limited information about the mechanical properties of the materials at different temperatures, humidity and ages, which is one of the main reasons that designers do not have any confidence in specifying RP materials for producing end-use parts.

Therefore, there is much work to be undertaken to convert the principles of additive manufacturing into viable manufacturing techniques that can be exploited more universally. However, despite the fact that true "RM" does not exist, there has been a significant increase in the use of RP technologies for end-use part manufacture which has mainly been afforded by the marked development of the processes and materials during the past 15 years. It is anticipated that true RM manufacturing systems will become available within a 5 to 10 year period and their introduction will truly amount to a new industrial revolution [Griffiths, 2002].

\subsection{Objective}

One of the main limitations facing RP parts end-use manufacture is the material properties of the parts produced. Improvements in material properties, most notably with SL, have allowed an increasing range of uses of SL and LS; however further improvements, particularly with respect to stiffness, strength and toughness are required to expand the envelope of applications.

Post-processing allows for improvements in material properties and performance of RP parts; however it does add time and cost to the manufacturing process. Various 
forms of post processing have been used to improve the performance of SL and LS parts including infiltration and cryogenic treatment [Fritz, 2001; Zarringhalam, 2003].

This paper investigates the use of electroplating to improve the properties of parts made by SL and LS to enable them to be used as end-use components.

\section{Background}

\subsection{Stereolithography}

Of the available RP processes, the stereolithography (SL) process has always been one of the most significant RP technologies and it is one of the technologies that is considered to be suitable as a future end-use part manufacturing process [Hague et al., 2003]. The SL technique is based on the process of photo-polymerisation, in which a liquid resin is converted to a solid polymer on exposure to computer controlled ultraviolet laser radiation [Jacobs, 1992]. The photopolymer is selectively cured on a layer by layer (additive) basis where the cured area corresponds to the desired cross-section of the required shaped article to be formed, which is in turn taken from the 3D CAD model of the part being produced. The solidified layer is then lowered by the amount of the required layer thickness and a recoating blade moves over the surface to apply a new layer of resin. The process is repeated until a green model of the required shape is finished. It should be noted that support structures are used to anchor the part to the build platform during the build process and to enable the production of over-hanging features. On completion of the build, the model is usually post-cured under high intensity ultraviolet radiation to complete the curing process. Thermal post curing is often, but not always employed to stabilise and improve the mechanical properties of the produced part, though the decision of whether to thermally post cure is dependent on the particular SL material being used. The use of a thermal post curing stage is in effect an accelerated ageing mechanism and can also have deleterious effects if not controlled correctly.

The main strength for SL lies in its ability to produce parts with tight tolerances and fine resolution when compared with other RP processes. However material properties tend to degrade over time. The application of a protective electroplated coating should add rigidity to parts and also reduce any effects of aging caused by absorption of water or ultra-violet light, however it may adversely affect feature resolution and tolerance.

\subsection{Laser Sintering}

Laser Sintering (LS) was first commercialised in the early 1990's and allows the production of parts using a wide variety of materials including polymers, metals and ceramics. The process works in a similar layer by layer approach to the SL process but instead of a liquid photopolymer, powdered materials are used. Laser sintering of polymers generally results in improved mechanical properties over those achieved in $\mathrm{SL}$, though unlike SL, the parts produced tend to be anisotropic in their material properties and thus more emphasis on the build direction is required. Resolution and accuracy of LS parts are not as good as their SL counterparts. 


\subsection{Electroplating}

Electroplating has been practiced for many years in industries such as electronics and jewellery manufacture. The process involves placing an anode and a cathode in a solution and applying a potential difference between them. Ions are discharged from the anode and bond to the cathode so that the cathode becomes plated by the metal from the anode [Kalpakjian, 1995].

\subsubsection{Electroplating non-conductive parts}

In order to plate the cathode it must be conductive. Consequently, polymer parts need to be coated in a conductive material. Initial plating of polymer parts may be by the application of silver paint [Arthur and Dickens, 1996]; copper and nickel filled conductive paints can also be used. Another method of coating polymer parts is by electroless deposition of metals such as nickel or copper. Other common methods used to make plastic parts conductive include rubbing with graphite or spraying with chemically reduced silver.

\subsubsection{Electroplating Materials}

A typical sequence used for decorative electroplating include copper as a base layer, followed by nickel and then a flash of chromium [ASTM B604-91, 1997]. Combinations of metals may be used to create alloys [Lowenheim, 1974]. The thickness of an electroplated coating may vary from a few atomic layers to $0.05 \mathrm{~mm}$ or more [Kalpakjian, 1995]. However, plating thickness can vary especially where the cathode has a complicated geometry including sharp corners. Electroplated finishes depend on a good bond to the substrate to hold them in place and their function is usually to enhance appearance or hardness or improve the corrosion resistance of the substrate surface. With a good bond to the substrate, high gloss finishes and/or very hard surfaces can be made but these plated layers are often very highly stressed, can be brittle and will flake off if there is a poor bond.

The materials used in this work are low stress acid copper and sulfamate nickel coatings that have been optimised for fabrication of freestanding structural parts via electroforming. These coatings are more tolerant of a weak bond to the substrate. These low stress coatings, running at close to room temperature, were chosen since it is not practical to optimise etching and bonding procedures for the large variety of materials used in RP particularly at the low volumes of parts produced.

\subsubsection{Geometrical Issues associated with electroplating}

Field strength in an electroplating bath affects plating thickness; there are always gradients in the field strength around a cathode in an electroplating bath but these can be minimized through the use of shields, auxiliary anodes and/or "thieves". Objects that are flat with no exposed corners will generally have the most uniform current distribution and hence produce a more even coating. If there are critical features on a part which are prone to excess metal build up, a field control element might be employed in that region. Finally, the areas that are most prone to metal build up are usually very exposed and accessible. Excess material can be removed from critical areas using small files so parts fit together properly.

\subsubsection{Electroplating Rapid Prototyped parts}

From the mid 1990's there has been some interest in electroplating SL parts for use as electrode discharge machining (EDM) electrodes [Ryall, 1996; Arthur et al., 1996; 
Soar and Dickens, 1996; Yarlagadda et al., 1999; Bocking et al., 2000]. The general view from this body of research suggests that great care is required and slow deposition rates employed in order to achieve an even electroplated coating especially where complicated geometries and deep slots are involved. Further, electroplated SL parts should be used cautiously with low amperages and wear rates in order to avoid over heating of the electrodes during the EDM process. None of this work however commented on the suitability of using electroplated parts for testing or end use manufacture.

Figure 1 shows some RP parts made by the Object process using an acrylate based photopolymer that have been electroplated. The threads on the parts in Figure 1 indicate the high degree of surface detail that may be maintained when RP parts are electroplated. The typical metal coating applied to RP parts is around $50 \mu \mathrm{m}$, which is usually less than the error on the model.

Take in Figure 1: Electroplated RP parts made by Acrylate based photopolymers

In order to take into consideration the thickness of the applied coating, it is possible to displace the CAD file surfaces inwards by the coating thickness. Also, most parts that have tight tolerance requirements or have specific locations that have to hold tighter tolerances (such as a hole diameter and location) and others that will not be as critical. In such cases, the holes can be opened up with an oversized drill to allow for plating or the hole might be masked so it is not plated and its dimensions are never changed.

Several multinational OEM's are using metal-coated RP models in engineering development of new products. The most extensive use is at Pitney Bowes Corp [Pitney]. Many parts in their products are designed to be manufactured from fibrereinforced plastics, die cast metal or sheet metal. While SL models are suitable for form and fit testing, they will often break prematurely or not function at all due to poor stiffness, strength and creep characteristics when used as part of a mechanism in dynamic testing. SL models plated with only $50 \mu \mathrm{m}$ of metal will function as well as the fibre reinforced plastic parts that are to be used in production. This allows several design iterations to be tested on loaded parts without having to resort to prototype tool manufacture and part moulding. SL models with $120 \mu \mathrm{m}$ of metal have been used for parts designed for die cast metal and have held up well in dynamic testing [Pitney]. However, when SL parts are used in very wet conditions, usually fail within days due to swelling. The absorption of water leads to a softening of the parts and therefore weaker mechanical properties [Saleh, 2003; Saleh, 2003]. This problem can be eliminated with metal coating.

Aerospace companies use coated RP models but in a somewhat different way. Large RP models are often made to create mock-ups of modules or vehicles in development. Since aerospace structures are usually made from stiff materials like aluminium or continuous fibre composites it is difficult to recreate the geometry in RP resins and obtain a stable part without resorting to significant modification of the geometry such as increasing wall thickness. The metal coating applied to RP models improves their durability while nearly eliminating creep and distortion often observed with very large RP models. Metal-coated RP models are also used to increase radar reflectivity and to improve durability in simulator components. 


\section{Methodology}

\subsection{Manufacture of Test Samples}

\subsubsection{Test Standards}

The mechanical properties investigated in this work included: Tensile (Young's modulus, ultimate tensile strength and \% elongation at break), and impact strength (using Izod tests). The tests were strictly conducted according to ISO standards [ISO 527, 1996; ISO 180, 2001] and all the test specimens were produced from 3D CAD models to the dimensions specified in the relevant standard.

\subsubsection{Production of Stereolithography Parts}

The equipment used to build the SL test samples was a SLA7000 by 3D Systems. The build volume for this machine is approximately $500 \mathrm{~mm} \times 500 \mathrm{~mm} \times 600 \mathrm{~mm}$ $(\mathrm{XYZ})$. Various parameters can be adjusted to optimise and customise the process for a specific task, with the most significant of these being "over-cure", "hatch-cure", layer thickness and the recoating parameters [Jacobs, 1992]. The definition and impact of each of these parameters are given elsewhere [Dulieu and Fulton, 2000]. However, it should be noted that the build parameters were provided and recommended by the resin suppliers and were used consistently for the test specimen's manufacture. The build styles used was based on the ACES (Accurate Clear Epoxy Solid) format which was designed specifically for use with epoxy resins.

30 tensile test parts were built upright from SL7560 Epoxy-based resin for this research, however they were built along with a further 720 parts in a single build. The total build time for 750 parts was 90 hours followed by 5 hours of manual finishing and 1.5 hours of post curing using a UV light box.

30 impact test parts were built from SL7560 resin for this research, however they were built along with a further 210 parts in a single build. The total build time for 240 parts was 7.2 hours followed by 2 hours of manual finishing and 1.5 hours of post curing using a UV light box.

After removal from the SL machine, both types of samples were cleaned by submerging them first in TPM for 30 minutes then in water for 30 minutes and then placing them in an ultrasonic tank containing TPM for 15 minutes.

\subsubsection{Production of Laser Sintered Parts}

The equipment used to build the LS parts was a Vanguard SI Laser Sintering system from 3D Systems. The build volume for this machine is approximately $355 \mathrm{~mm} \times 305 \mathrm{~mm} \times 430 \mathrm{~mm}(\mathrm{XYZ})$. The parts were built using virgin Duraform PA powder.

For this work, 30 tensile test parts were built in the vertical build orientation. It is recognised that for the LS process that build orientation affects the isotropy I anisotropy of the resultant parts and thus the weaker orientation was chosen.

30 impact test parts were built from Duraform powder for this research and were subsequently mechanically notched. 


\subsection{Electroplating}

Once the parts were finished they were shipped to be electroplated with different thicknesses of copper/nickel. Prior to the electroplating process the parts were made conductive by electroless plating of nickel - this was chosen as it provides a better bond than painting a silver coating. Electroless plating of nickel involved a sequence of preparatory steps before coating the parts in a Room Temperature Electroless Nickel (RTEN) batch for 20 minutes, this results in a nickel coating of nominally $1 \mu \mathrm{m}$.

The subsequent electroplating process involved coating the parts with copper followed by nickel. This is to make a laminate coating with the two metals in equal proportions. Table I summarises the parts made and parameters used to apply coatings. After electroplating the parts were lightly filed in positions where small lumps of copper had amalgamated.

Take in Table I: Electroplating parameters for tensile and impact specimens

\subsection{Measurement of Electroplated Material Thickness}

While Table I shows the intended thickness of electroplated material the true thickness was measured using an eddy current sensor. The sensor used was an ISOSCOPE MP3-CU (see Figure 2) and it was used to measure the thickness of metal on top of the non-conductive RP part, this includes the layer of electroless plated nickel which was minimal when compared with the thickness of electroplated copper/nickel. The sensor was quoted to have an accurate working range from 0 $150 \mu \mathrm{m}$ with a resolution of $1 \mu \mathrm{m}$ and a maximum reading of $176 \mu \mathrm{m}$.

Take in Figure 2: Eddy Current Sensor in place over a coated sample

For each specimen, 5 readings for thickness were taken at positions that were not close to any edges. Care was taken to ensure that readings were not taken in positions where lumps of copper had been filed away after electroplating.

\subsection{Surface Roughness}

One drawback often associated with RP parts is surface roughness. LS parts have uniform but rough surfaces when compared with their SL counterparts. Plated samples were subjected to surface roughness tests using a Talysurf profilometer. For each of the sample sets shown in Table I, 3 parts were selected at random and on each of these 3 separate readings of surface roughness (Ra) were recorded at positions away from any edges. An optical microscope was also used to qualitatively assess the deposition of metal and its effect on surface roughness.

\subsection{Prediction of Mechanical Response of Plated Parts}

Electroplating a polymer part creates a composite product and the standard composite theory was used to predict the mechanical response of the tensile specimens produced. Assuming there is strain compatibility between the constituent parts, the rule of mixtures allows the prediction of Young's modulus of a composite given the cross sectional area of the component materials and their respective Young's modulus values using the equation shown below [Hyer, 1998]: 


$$
E=E^{f} \cdot V^{f}=+E^{m}\left(1-V^{f}\right)
$$

Where:

$E=$ Young's modulus for the composite

$E^{f} .=$ Young's modulus for the filler

$\mathrm{V}^{\mathrm{f}}=$ Volume fraction of the filler (cross sectional area)

$E^{m}=$ Young's modulus for the matrix

However in this case the RP part is plated by copper and then by nickel (the propsed electroless deposited nickel may be discounted as it's thickness is negligible) and so equation (1) must have an extra term added to account for the third component material. Figure 3 shows a schematic that was used to calculate the volume fractions of the different component materials.

The area fractions of each of the component materials shown in Figure 3 were calculated as shown below:

Total Area $=A_{t}=\left(10+2 T_{c}+2 T_{n}\right) \times\left(4+c+2 T_{n}\right)$

Area fraction of polymer $A_{p}=(10 \times 4) / A_{t}$

Area fraction of copper $A_{c}=\left[\left(10+2 T_{c}\right) \times\left(4+2 T_{c}\right)-A_{p}\right] / A_{t}$

Area fraction of nickel $A_{n}=\left[A_{t}-\left(10+2 T_{c}\right) \times\left(4+2 T_{c}\right)\right] / A_{t}$

The Young's modulus for each part was calculated using the following equation using the area fractions described above and in Figure 3:

Where:

$$
E=E_{p} \cdot A_{p}+E_{c} \cdot A_{c}+E_{n} \cdot A_{n}
$$

$E_{p}=$ Young's Modulus for the RP polymer part

$E_{c}=$ Young's Modulus of copper

$E_{n}=$ Young's Modulus of nickel

Take in Figure 3: Schematic of cross-section of coated tensile test part

\subsection{Test Procedure}

All the tests were conducted in a temperature and humidity controlled room. The tensile and flexural tests were performed on a Zwick 1030 [Zwick, 2003] tensile test machine with a nitrogen facility for low temperature tests combined with a Zwick heated cabinet for the higher temperature tests. A Zwick 5102 pendulum impact tester, configured for Izod tests was used for impact analysis.

\section{Results}

\subsection{Electroplated Material Thickness}

Table II shows the percentage of the total metal volume, the average, standard deviation (STDEV) and range of measured thickness of electroplated material for each of the target thicknesses on SL and LS tensile test parts. 
Table II shows that, for all sets of parts tested, the average thickness was within $10 \mu \mathrm{m}$ of the target thickness. The results for standard deviation and range in Table II show that as coating thickness is increased the control of tolerances of thickness are reduced. The ranges of coating applied reached a maximum of $42 \mu \mathrm{m}$ for the SL parts with a target thickness of $120 \mu \mathrm{m}$, this range is tighter than may be expected to be achieved from the RP parts itself indicating that electroplating should not have an adverse affect on tolerances that may be achieved.

Figure 4 shows the measured thickness plotted against the target thickness for all stereolithography samples. This indicates that there was a tendency to over plate at the lower target thickness of $20 \mu \mathrm{m}$ and a tendency to under plate at the higher target thickness of $120 \mu \mathrm{m}$.

Take in Figure 4: Measured thickness plotted against the target thickness for all stereolithography samples

Figure 5 shows the measured thickness plotted against the target thickness for all laser-sintered samples. As with the stereolithography samples this shows that there was a tendency to over plate at the lower target thickness of $20 \mu \mathrm{m}$ and a tendency to under plate at the higher target thickness of $120 \mu \mathrm{m}$.

Take in Figure 5: Measured thickness plotted against the target thickness for all laser sintered samples

Figure 4 and Figure 5 both show that the range of plating thickness increases with total material deposited, this may create a tolerance issue for parts with thicker plating.

\subsection{Surface Roughness}

Figure 6 shows Optical microscope pictures of sections of the coated stereolithography samples. These images show that an equal coating of copper and nickel were deposited on each sample.

Take in Figure 6: Optical microscope pictures of sections of coated stereolithography samples

Figure 7 shows optical microscope pictures of sections of coated laser sintered samples. These images are in marked contrast to those for the stereolithography parts and show how the surface roughness of the RP part leads to a complicated pattern of deposition. The effect of the increased layers is to smooth out the surface roughness of the surface of these parts but once again there appears to be an equal overall deposition of copper and nickel.

Take in Figure 7: Optical microscope pictures of sections of coated laser sintered samples

Figure 8 shows the surface roughness measured from both stereolithography and laser sintered samples. The stereolithography samples are much smoother than their laser sintered counterparts as might be expected given the roughness of parts produced by the processes and the images shown in Figure 6 and Figure 7. With stereolithography parts the roughness shows a small increase as layer thickness increases, however the converse is true for laser-sintered parts as supported in Figures 11 and 12 . The electroplating process clearly has the effect of smoothing the rough parts produced by laser sintering and so, as more metal is deposited, then less the of the original roughness remains. 


\subsection{Prediction of Response of Plated Parts}

The values of Young's Modulus are shown in Table III. Equation 2 was used to calculate the effective/composite Young's Modulus for the parts produced. Calculations assumed that the target dimension for manufacture of SL/LS parts and plating thicknesses were achieved. The values of Young's Modulus used are shown in Table III.

Take in Table III: Values for Young's Modulus used in calculations to predict response

Table IV shows the predicted values for Young's Modulus found form equation 2 for electroplated stereolithography and laser sintered samples. As expected the results predict a significant increase in stiffness with thicker electroplated coatings. Also as parts made from SL7560 are stiffer than those made by Duraform the stereolithography parts were predicted to have a higher Young's modulus than their laser sintered counterparts.

Take in Table IV: Predicted values of Young's Modulus for electroplated stereolithography and laser sintered samples

\subsection{Tensile Tests}

Figure 9 shows the predicted and measured values for Young's modulus for the coated stereolithography and laser sintered tensile test parts. As expected the samples with thicker coatings had higher Young's modulus. The predicted values rise more sharply with increased plating thickness than the actual values, this may be due to the fact that under higher loads there is some slipping between different material layers and so the assumption of strain compatibility becomes invalid.

Take in Figure 9: Predicted and measured values for Young's modulus for the coated stereolithography and laser sintered tensile test parts

Figure 10 shows the UTS recorded for the stereolithography and laser sintered samples. Again thicker coatings lead to higher mechanical properties as would be expected although there does not appear to be any convergence of the trend-lines as the volume fraction of the metal increases.

Take in Figure 10: UTS recorded for the stereolithography and laser sintered samples

Figure 11 shows the elongation at break results from the plated stereolithography and laser-sintered samples.

Take in Figure 11: Elongation at break results from the plated stereolithography and laser-sintered samples

The elongation results show that increasing plating thickness results in a low elongation for laser sintered parts and an increase value for stereolithography parts. For low plating thickness the elongation values are similar to those for uncoated samples ( $\sim 5 \%$ for stereolithography and $\sim 8 \%$ for laser sintering) as might be 
expected. The trend-lines suggest a convergence of elongation at break in the region of $5-6 \%$ for parts coated with thicker layers of copper and nickel.

\subsection{Impact Tests}

Figure 12 shows the results from the impact tests with laser-sintered parts having higher impact strength than stereolithography parts. As with the results for measured thickness of electroplated material, there is an increase in variability as the target thickness is increase from $20 \mu \mathrm{m}$ to $120 \mu \mathrm{m}$. The trend-lines in Figure 12 also show how the average impact results appear to converge - this may be due to the coating materials which are the same for both types of RP part becoming more dominant in affecting the properties of the composite parts.

Take in Figure 12: Results from impact tests with stereolithography and laser sintered parts

\section{Conclusions}

Coatings of copper and nickel on stereolithography and laser sintered parts result in increases in Young's modulus, UTS and impact strength; they also tend to smooth the surface of laser-sintered parts. The increase in Young's Modulus of the composite after applying the coating is only $2 / 3$ the amount expected for the LS materials and just over half the expected stiffening in SL material base on a rule of mixtures prediction. Ultimate tensile strength of the composites on the other hand followed a rule of mixtures prediction very well. The effects of plating on elongation at break are less pronounced and tend to a value $\sim 5 \%$ for thicker coatings. The effect of electroplating on part tolerance was not significant for the parts made in this work; however for more complicated geometries and thicker coating then tolerance of coatings may be an issue.

The improvements of mechanical properties given by electroplating stereolithography and laser sintered parts should lead to increase use for functional prototypes and end use products made by these processes. It should be noted that, the rule of mixtures theory shows that the percentage volume of metal applied dictates the preferred properties. Consequently if parts of a greater cross-section are used then the effect of the plated metal decreases.

\section{References}

Arthur A and Dickens PM (1996), "Material Removal and Tool Wear Rates in EDM with Stereolithography Electrodes", Proceedings from the $5^{\text {th }}$ European Conference on Rapid Prototyping and Manufacture, Helsinki, Finland, 4-6 June 1996, pp 157169, ISBN 0951975951

Arthur A, Romero Carol J, Dickens PM and Cobb R (1996), "Rapid EDM electrodes using stereolithography models - combining pin matrix and electroplating techniques", $2^{\text {nd }}$ National Conference on Development in Rapid Prototyping and Tooling, Buckinghamshire College, UK, 18-19 November 1996, pp 161-169 
ASTM B604-91 (Re-approved 1997), Standard Specification for Decorative Electroplated Coatings of Copper Plus Nickel Plus Chromium on Plastics, ASTM.

Bocking CE,. Rennie AEW and Bennett GR (2000), "Relationships between wall thickness and erosion depth of thin walled electroformed EDM electrodes produced from RP models", Proceedings from the SFF Symposium, August 7-9 2000, pp469477, ISSN 1053-2153.

Cooper, K.G., 2001, Rapid Prototyping Technology-Selection and Application (New York: Marcel Decker Inc.)

Dulieu-Barton, J.M. and Fulton, M.C., (2000), "Mechanical Properties of a typical Stereolithography Resin", Journal of Strain, Vol: 36, No: 2, pp.81-87.

Fritz, B. (2001), "Effects of Cryogenic Aging on Rapid Prototyping Materials", Proceedings from the SLS User Group Meeting, San Francisco, UAS, September 29 - October 2.

Griffiths, A., (2002), "Rapid Manufacturing, the next industrial revolution", Journal of Materials World, Vol:10, no: 12, pp.34-35.

Groover, M.P., (2002), "Fundamentals of Modern Manufacturing Materials, Processes and Systems", John Willey \& Sons Inc., New York, pp.772-785.

Hague, R.J., Campbell, R.I. and Dickens, P.M., (2003), "Implications on Design of Rapid Manufacturing", Proceedings of the Institution of Mechanical Engineers Part C: Journal of Mechanical Engineering Science, 217(C1), pp 25-30

Hague, R., (Feb 2002), "Design for Rapid Manufacturing presentation", Stereolithography Annual User Group (SLUG), Costa Mesa.

Hyer, MW., (1998), "Stress Analysis of Fiber Reinforced Composite Materials", McGraw-Hill International Editions, ISBN 0-07-115983-5.

ISO 180, Plastics - Determination of IZOD impact strength 2001

ISO $527-1$ and 2, Plastics - Determination of tensile properties, 1996

Jacobs, P. F., (1992), "Fundamentals of Stereolithography", Society of Manufacturing Engineers, Dearborn, Michigan, USA

Kalpakjian, S (1995), "Manufacturing Engineering and Technology", Addison-Wesley Publishing Company, USA, ISBN 0-210-53846-6

Lowenheim, F. A., (1974), "Modern Electroplating", John Wiley \& Sons Inc., $3^{\text {rd }}$ Edition, P. 486-551.

Masers, M. and Mathy, M., (April 2002) "Direct Manufacturing of Custom - made hearing instruments, an implementation of Digital Mechanical processing", SME RP and RM Conference, Cincinnati. 
Pitney Bows Corp., 100 Barr Harbor Drive, PO Box C700, West Conshohocken, PA 19428-2959, United States.

Ryall C (1996), "Rapid EDM Electrodes: linking rapid prototyping to high volume production", Proceedings from the $1^{\text {st }}$ National Conference on Development in Rapid Prototyping and Tooling, Buckinghamshire College, UK, 6-7 November 1995, pp 211-219

Saleh, N., (Nov. 2003), "Material Properties Report: Accura SI40 Mechanical Properties Under Differing Humidity Conditions \& Ageing Characteristics", Materials Analysis \& Design Optimisation for Rapid Manufacturing Project, Copyright - Rapid Manufacturing Research Group, Loughborough University.

Saleh, N., (Nov. 2003), "Material Properties Report: SL7560 Mechanical Properties Under Differing Humidity Conditions \& Ageing Characteristics", Materials Analysis \& Design Optimisation for Rapid Manufacturing Project, Copyright - Rapid Manufacturing Research Group, Loughborough University.

Soar RC and Dickens PM (1996), "Finishing laminate tooling with stereolithography EDM electrodes", Proceedings from the $5^{\text {th }}$ European Conference on Rapid Prototyping and Manufacture, Helsinki, Finland, 4-6 June 1996, pp 87-107, ISBN 0 951975951

Wholers, T., (2001), Wholers Report, "Rapid Prototyping and Tooling, State of the Industry", Annual worldwide progress report, Wholers Associate Inc. USA.

Yarlagadda PKDV, Subramanian V \& Christodoulou P (1999), "Feasibility studies on production of electro-discharge machining electrodes by stereolithography and electroforming process", Journal of Materials Processing Technology, v.89, pp.231237, ISSN 0924-0136.

Zarringhalam, H., (May 2003), "Post Processing of Duraform Nylon SLS pasrts for tensile and impact strength improvement", Final Year Dissertation submitted to Loughborough University.

Zwick- Roell www.zwick.com, 2003 